\title{
The influence of dietary immunomodulatory factors on development of food allergy in children
}

\author{
Izabela Sardecka1 , Aneta Krogulska², Ewa Toporowska-Kowalska ${ }^{1}$
}

1Department of Paediatric Allergology, Gastroenterology and Nutrition, $3^{\text {rd }}$ Chair of Paediatrics, Medical University of Lodz, Lodz, Poland ${ }^{2}$ Department of Paediatry, Allergology and Gastroenterology, Ludwik Rydygier Collegium Medicum in Bydgoszcz, Nicolaus Copernicus University in Torun, Poland

Adv Dermatol Allergol 2017; XXXIV (2): 89-96

DOI: https://doi.org/10.5114/pdia.2016.63955

\begin{abstract}
In the last few years many studies have been conducted on the role of dietary and environmental factors in the prevention of allergic diseases among children. Many studies have shown that the diet of pregnant women and children in their early postnatal life, rich in antioxidants, vitamin D, and fatty acids is beneficial as it reduces the risk of allergy in their future life. Moreover, there are many reports about the main role of gut microbiota and probiotics in the allergy prevention, what can indicate new ways of procedures in allergic diseases.
\end{abstract}

Key words: food allergy, diet, immunomodulatory factors, children.

\section{Epigenetic changes and development of food allergy}

For the last 30-40 years we have been observing a growing number of episodes of allergic diseases, which might result from disturbances on the pathway of many immune reactions, contributing to the occurrence of the diseases [1, 2]. Studies on human genome still have not clearly explained the pathogenesis of the increased incidence of allergy. Recently researchers have considered epigenetic changes to play a role in this process as they determine the phenotype much more than the sequence of human genome [3]. Epigenetic information refers to hereditary changes in the function of genes which are passed on to daughter cells but which do not result from changes in the DNA sequence but chromatin modifications. Study findings imply a crucial impact of pre- and post-natal factors on a change in the gene expression, which leads to permanent changes in many immune reactions and increased susceptibility to allergic diseases [4]. There is evidence that changes in the gene expression are induced by epigenetic mechanisms [5]. Many of the same factors (such as: exposure to microorganisms, dietary factors, environmental pollution) greatly contribute to the occurrence of both allergic and autoimmune diseases. This implies an early role of the above factors in major immune reactions, common for the development of allergic and autoimmune diseases [3]. Epigenetic changes, by affecting the process of cell differentiation, determine the individual's development and phenotype. There are three major mechanisms of epigenetic regulation: modifications in the DNA structure, modifications of histone proteins and the so-called "small RNA". These processes result in changes in the methylation of DNA and histone, and histone acetylation and consequently in the degree of DNA compaction, what allows for gene transcription by regulating their expression [6]. Genetically identical parent cells can thus produce many daughter cells that are morphologically and functionally different. Encoded changes in the gene expression are passed during mitosis. It was confirmed that T lymphocytes differentiation closely depends on these changes [7]. Epigenetic mechanisms regulate differentiation of Th1 and Th2 lymphocytes [8-12]. Moreover, changes in promoter methylation processes contribute to changes in the expression of the Foxp3 transcription factor and thus induce Treg lymphocyte differentiation $[13,14]$. Treg lymphocytes are responsible for regulation of the function of other lymphocytes, which prevents induction of excessive immune reactions, underlying autoimmune or inflammatory diseases of a body. Treg lymphocytes inhibit the activity of Th1, Th2 and Th17 lymphocytes; they induce dendritic cells (CDs) to release IL-10, and B lymphocytes to release IgG4 immunoglobulin. Moreover, Treg lymphocytes are characterized with suppressor activity

Address for correspondence: Izabela Sardecka MD, Department of Paediatric Allergology, Gastroenterology and Nutrition, $3^{\text {rd }}$ Chair of Paediatrics, Medical University of Lodz, 36/50 Sporna St, 91-738 Lodz, Poland, phone: +48 4261777 27, e-mail: izabela.sardecka@onet.pl Received: 2.02.2016, accepted: 20.04.2016. 
for mast cells, basophils and eosinophils. Due to these mechanisms of Treg lymphocytes a human does not develop hypersensitivity to food allergens [15]. It should be pointed out that functions of Treg lymphocytes are much limited in infancy and early childhood in comparison to adulthood [16-18].

\section{Immunomodulatory factors}

\section{Microbiome}

Changes in the microbiome are one of the most crucial factors which determine development of allergic diseases [19]. In the foetal period contact with pathogenic and non-pathogenic metabolites of microorganisms in the gut-associated lymphoid tissue (GALT), colonizing the gastrointestinal tract, might prevent allergic diseases in offspring [20, 21]. It was confirmed that pregnant women living in rural areas have a greater number of Treg cells through increased DNA methylation in the Treg-specific differentially methylated region (TSDR), which decreases the risk of allergic diseases in their offspring [22]. The same effects were observed in children who stayed in a close contact with farm animals. Results of GABRIELA or PARSIFAL studies unambiguously indicate that the risk of atopy or asthma in later life was much lower in children exposed to environmental microorganisms than in children who were raised in cities [23, 24].

\section{Diet}

A diet is another factor which is becoming more and more crucial for development of allergic diseases. It is believed that a shift in dietary models, i.e. replacing a traditional diet consisting of fresh vegetables, fruit and fish with a modern one, i.e. a diet containing synthetic and processed food products, increases the incidence of allergic diseases. It was confirmed that diet components affect the functioning of the immune system; they in crease the activity of phagocytes, NK cells, lymphocytes and also activate the production of immunoglobulins [25]. Besides, diet components modulate the function of the immune system through epigenetic mechanisms and lead to changes in the gene expression [26]. What is even more important, a diet determines the quality of microbiota which colonizes the digestive tract. By comparing two populations which demonstrate different eating habits, one living in rural African areas and the other living in Europe, De Flippo confirmed a relationship between the composition of the microbiota and the diet. Bacteroides strains were dominant in the African population whereas in the European one, Firmicutes strains prevailed. These changes were also connected with faecal excretion of short chain fatty acids (SCFA), which played an important role in immunomodulation [27]. The attempt to replace "the hygienic hypothesis", which has been a common belief, with "the dietary hypothesis", proves a growing role of a diet in the development of allergic diseases. Such a replacement has been made on the basis of a longterm observation of a relationship between the diet and the incidence of allergic diseases. Researchers noted that the incidence of asthma in countries that are comparable in terms of hygiene standards, i.e. in Japan and the United States, is different. It is much higher in the latter. Populations in these two countries have completely different diets. In America people consume mostly high-fat foods, poor in antioxidants, whereas in Japan a diet rich in salt water fish and fresh vegetables dominates.

Not only is the composition of a diet, but also duration of exposure to allergens is important for the allergy development. In the $20^{\text {th }}$ century in infants from allergy risk groups, major allergenic foods were either eliminated or their introduction was delayed. This management strategy appeared to be wrong. Currently, it is believed that early exposure to food allergens is preventive in development of food allergy. Consumption of food products such as milk, wheat and peanuts by pregnant women in their early pregnancy reduced the risk of asthma and allergy in their offspring [28]. Results of an extensive randomized clinical study, called Learning Early about Peanut Allergy (LEAP), confirmed that early and systematic consumption of peanuts significantly decreased the risk of the development of asthma and allergy in children from a high-risk group, evaluated in their fifth year of life [29]. It is still unknown whether early introduction (in the $3^{\text {rd }}$ month of life) of alimentary products such as milk, eggs, fish, wheat, sesame, peanuts into infants' diet, accompanied by breastfeeding, in comparison to late introduction (in the $6^{\text {th }}$ month of life) of the above products has any impact on the development of food allergy, asthma, atopic dermatitis, allergic rhinitis in the $3^{\text {rd }}$ month of life. The Enquiring About Tolerance (EAT) study is supposed to resolve this dilemma.

A lot of dietary factors have been proved to affect the functioning of the immune system. They include longchain polyunsaturated fatty acids (LCPUFAs), prebiotics, probiotics, antioxidants, vitamins and folates [30]. Female milk is the most important component of a diet. It is a source of many immunomodulatory factors which induce food tolerance. Due to the content of immunoglobulin, lactoferrin, lysozyme, oligosaccharides, LCPUFAs, cytokines, nucleotides, hormones, antioxidants or immune cells, female milk plays a crucial role in the prevention of allergic diseases [31, 32]. Breast milk contains up to $10^{9}$ microorganisms in one litre. The most common are: Staphylococci, Streptococci, Corynebacteria, Lactobacilli, Micrococci, Propionibacteria, and Bifidobacteria [30]. The last strain has been confirmed to greatly affect the development of GALT [30].

According to Devereux, dietary factors introduced in the foetal period, rather than in the postnatal period, play a highly important role in prevention of allergic diseases [33]. Eating habits, elimination diets and limited 
supply of many alimentary products arising out of such diets might contribute to an increased risk of allergy in offspring. Studies on the role of a diet in the prevention of allergy are still being conducted and findings confirming preventive properties of certain foods and their effect on subsiding or exacerbation of allergic symptoms in offspring are often conflicting.

\section{Dietary immunomodulatory factors Probiotics}

Probiotics have an ability to adhere to intraepithelial lymphocytes (IELs). By doing this they modulate the composition of microbiome. The adhesion ability, mainly of lactic acid, promotes trapping of probiotics by Payer's patches and due to that fact probiotics activate and stimulate proliferation of dendritic cells (DCs). Activated dendritic cells promote the $T$ lymphocyte response and production of IL-10 and IL-12, anti-inflammatory cytokines. Bearing in mind the relationship between microbiome and development of allergy, scientists have been conducting studies on the effect of probiotics since the 1990s [34, 35]. The first report presented by Majama and Isolauri showed a reduction of atopic dermatitis in children after 1-month supplementation with Lactobacillus rhamnosus [36]. Studies conducted in 2007 in Italy on 187 kindergarten children with asthma and allergic rhinitis revealed a positive correlation with longer remission periods in those children who consumed milk with Lactobacillus casei rather than in those who were administered placebo [37]. Björkstén et al. noticed that two-year old children with allergy demonstrate a considerable amount of Staphylococcus aureus in GALT and a small amount of Bifidobacteria [38]. Similar observations were made by Sjögren 10 years later. She also noticed a greater amount of Clostridium bacteria [39]. Kong et al. revealed that infants with IgE-dependent allergy and non-IgE dependent allergy demonstrated a smaller number of Bacteroides, Proteobacteria and Actinobacteria [40]. After detecting differences in microbiome Kalliomäki et al. proposed that pregnant women and babies in their early post-natal period should be administered probiotics orally because such management decreases the incidence of eczema in infants by as much as 50\% [41]. Kalliomäki et al. also noticed that supplementation with Lactobacillus GG in breastfeeding mothers and in infants up to the $6^{\text {th }}$ month of life had a beneficial effect on the prevention of atopy, reduction of asthma and eczema in high-risk children in comparison with the placebo group [41]. Similar studies conducted in 2001-2009 revealed that consumption of probiotics by pregnant women and infants prevents 2-7 year-old children from developing atopic dermatitis [42]. Kukkonen et al. made a study on pregnant women who were administered complex probiotics (Lactobacillus rhamnosus, Bifidobacterium breve and Propionibacterium freudenreichii). The probiotics did not appear to prevent
IgE-dependent diseases in children up to two years old but they were proved to significantly decrease the risk of atopic dermatitis [43]. Results of studies on a relationship between probiotics and development of allergic diseases are often contradictory. Kopp et al. observed that supplementation with Lactobacillus GG in pregnant women and infants did not result in a decreased number of atopic cases and episodes of allergic exacerbation in children. What is more, they observed that the supplementation contributed to an increased incidence of wheezing [44]. Another study, which included 50 pregnant women, who were administered probiotics in their late pregnancy, did not confirm an effect on the GALT composition in their offspring after a seven-day breastfeeding period in comparison with the control group [45]. According to some more reports, oral supplementation with Lactobacillus GG in children aged 6-24 months with recurrent wheezing and a positive family history of allergy, did not reduce the risk of asthma or atopic dermatitis [46]. Arslanoglu et al. observed that early supplementation with a mixture of probiotic oligosaccharides decreases the risk of allergy in children in the first 2 years of life [47].

A meta-analysis of a randomized controlled trial (RCT) confirmed a preventive effect of supplementation with Lactobacillus rhamnosus GG probiotic on atopic dermatitis, particularly in combined administration in pregnancy and in the post-natal period, especially in infants from the risk group. It was however emphasized that no repeatable studies are available for other probiotics. It was also added that there are no data on any potential preventive effect on other allergic diseases. Besides, researchers noticed that more and more studies are confirming a beneficial effect of prebiotics [48].

\section{Antioxidants and vitamin D}

In the 1990s, a study was published in which the authors claimed that small consumption of fruit and vegetables increases the risk of allergic diseases [49, 50]. Since then a lot of studies on the role of particular foods in development of allergy and a relationship between a diet and allergic diseases have been published [51-55]. The so-called "western diet", rich in fat but poor in vegetables and fruit, is becoming more and more common. As a consequence, the consumption of antioxidants in a daily diet gets smaller, which might result in increased susceptibility to asthma [56]. Scientists noted a role of particular vitamins on functioning of the human immune system. Vitamin A promotes differentiation of monocytes, neutrophils and lymphocytes, including Treg lymphocytes $[57,58]$. Moreover, it maintains the integrity of mucous membranes, haematopoiesis, production of antibodies, and transforming growth factor $\beta$ (TGF- $\beta$ ). It also regulates the function of $B$ and T lymphocytes, NK cells, neutrophils, macrophages and is a modulator of gene transcription $[57,58]$. A diet rich in retinoids increases phagocytic functions of macrophages and production of 


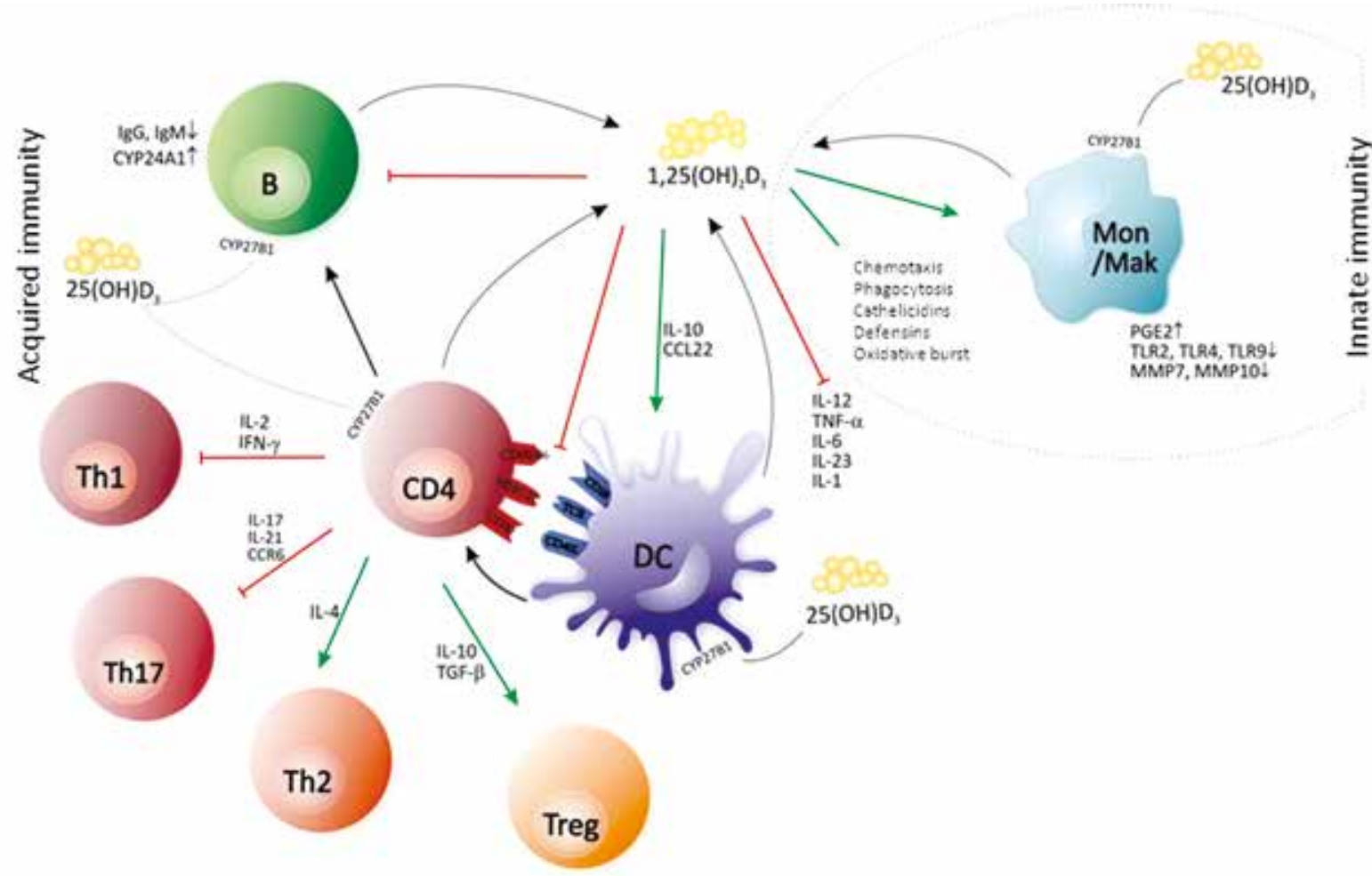

Figure 1. The immunomodulatory effect of vitamin D

TGF- $\beta$ [59]. An insufficient amount of vitamin A contributes to a decreased subpopulation of CD4 cells and a decreased CD4/CD8 ratio [60]. $\beta$-carotene, by increasing MHC class II expression, stimulates the cellular response [59]. Vitamin C stimulates a synthesis of prostaglandins and cytokines and inhibits the activity of histamine as well as the expression of pro-inflammatory cytokines (IL-6, TNF- $\alpha$ ). Moreover, it promotes Th1 lymphocytes and inhibits Th2 lymphocytes.

Studies performed in Scotland revealed that consumption of vitamin $C$ by pregnant women decreased the risk of wheezing and eczema in children up to the age of 2 years [61]. The study also demonstrated that consumption of Zinc in the foetal period decreased the risk of asthma and eczema in the women's offspring. A clear relationship between consumption of vegetables and fruit by pregnant women and a decreased risk of atopy in children was not observed. However, a high consumption of apples appeared to be a preventive factor in the development of asthma $[62,63]$. According to Nurmatov, there is very little evidence that some foods and nutrients prevent asthma and allergic diseases. However, vitamins: A, D, E and Zinc as well as fruit and vegetables included in the Mediterranean diet possibly prevent asthma [64].

Vitamin E, found in fats and oils (mainly in those containing polyunsaturated fatty acids - PUFAs), is responsible for the integrity of cell membranes; it inhibits the activity of nuclear factor $\kappa$-light-chain-enhancer of activated $B$ cells (NF- $\kappa B$ ), stimulates the production of antibodies, lymphocyte proliferation, activity of NK cells and phagocytic activity of macrophages. Studies conducted in the United States revealed that consumption of vitamin $\mathrm{E}$ and Zinc by pregnant women reduced the risk of wheezing in their offspring [62]. Some other studies, carried out in Germany, did not confirm a relationship between a diet rich in vegetables and fruit kept by pregnant women and a decreased eczema in their children at the age of two [65].

The active form of vitamin $\mathrm{D}_{3}: 1,25(\mathrm{OH})_{2} \mathrm{D}$ induces the innate immune response by stimulating the function of macrophages (their chemotactic and phagocytic properties) as well as by the increased production of antibacterial peptides, i.e. cathelicidins. It also affects the specific response, by inhibiting maturation and differentiation of DCs. Th1 and Th17 cells start secreting less cytokines, whereas the secretion of cytokines by Th2 cells gets increased. The vitamin stimulates the development of Treg cells by the activation of DCs. It also reduces IgG and IgM production by the plasmocytes (Figure 1). Vitamin D induces tolerogenic DCs [66], which regulate immunoglobulin-like transcript receptors ILT3 and ILT4 [67]. Expression of these receptors inhibits the activation of NF- $\kappa \mathrm{B}$, which is a major transcription factor, responsible for inflammatory processes in a human body $[68,69]$. 
It was revealed that supplementation with vitamin $D_{3}$ in the fetal period protects against the development of atopy and wheezing in children aged $3-5$ years [70-73]. Post-natal supplementation did not appear to be that effective, which resulted in initiating studies on the effect of vitamin $D_{3}$ supply in pregnant women on inducing the production of tolerogenic DCs in the women's offspring. Some researchers in Finland and France conducted studies in which they measured the level of ILT3 and ILT4 expression in the cord blood. Results of the studies showed that supplementation of vitamin $\mathrm{D}_{3}$ had a beneficial effect in higher expression of these genes [74].

\section{Fatty acids}

Fatty acids are divided into saturated and unsaturated acids. Unsaturated acids include PUFAs. The PUFAs in turn can be classified into essential fatty acids, which include linoleic acid and $\alpha$-linolenic acid, and into long-chain polyunsaturated fatty acids (LC-PUFAs), which include omega-3 and omega- 6 acids. Omega-3 acids are characterized with anti-inflammatory properties, whereas omega- 6 acids - with pro-inflammatory properties. Saturated fatty acids include short-chain fatty acids (SCFAs).

\section{Polyunsaturated fatty acids}

The PUFAs regulate functions of DCs; they increase their anti-inflammatory properties. PUFAs stimulate Treg lymphocytes. They have an influence on eicosanoid metabolites. By regulating the expression of pro-inflammatory cytokines, they decrease their production. They are precursors of anti-inflammatory mediators: resolvins and protectins. They also inhibit release of free radicals and expression of $\mathrm{MCH}$ class I and II antigens [75-78]. A diet rich in omega- 6 acids (found in vegetable fats, rich in linoleic acid) contributes to a high level of arachidonic acid in tissues, which in turn, contributes to an increased production of eicosanoids, including prostaglandin E2. This cytokine increases synthesis of Th2 lymphocytes and production of IgE antibodies. A diet rich in omega-3 acids decreases the pro-inflammatory response.

Studies conducted in Australia confirmed a beneficial effect of a diet rich in fatty fish, containing a lot of omega-3 acids. This kind of diet helped to reduce the incidence of asthma and other allergic diseases in early childhood [79-81]. Children who consumed fish at least twice a week less frequently demonstrated episodes of bronchial hyperreactivity [79]. Furuhjelm et al. obtained similar results. In his study he included women who were 25 weeks pregnant. They were supplemented with omega-3 acids. He discovered that children of those women less frequently developed IgE-dependent eczema than children from the control group [82]. A similar study was conducted in Australia. The authors of the study confirmed that supplementation with LCPUFA n-3 in preg- nant women prevented occurrence of IgE-dependent allergy in their children (both eczema and food allergy). The study comprised children in the $12^{\text {th }}$ month of life, from a high-risk group.

Authors of the so-called Childhood Asthma Prevention Study (CASP) obtained different results. The children in their early childhood included in the study were divided into two groups. Group I was administered supplements rich in omega- 3 acids and poor in omega- 6 acids. Group II was administered supplements rich in omega- 6 acids. Finally, at the age of 5 the children from group I did not report decreased susceptibility to atopy or asthma in comparison with group II [83]. Nagakura et al. revealed that a diet rich in omega-3 acids applied in asthmatic children reduces the severity of the disease [84] although in his study he included children whose exposure to inhaled allergens and applied diet was closely controlled. Hodge et al. supplemented children aged 8-12 years with omega-3 acids for a period of 6 months. The children demonstrated a high level of the acids in the blood serum. Yet, this fact did not have implications on the asthma severity in those children [85]. It seems that different observations with regard to the protective properties of omega-3 acids and occurrence or development of allergic diseases might result from different doses of fatty acids administered in the studies. Nagakura et al. adjusted the doses to the patient's body weight but Hodge administered each patient the same amounts of docosahexaenoic and eicosapentaenoic acids. Nevertheless, in both studies the authors evaluated patients with stabilized asthma and the applied doses were much higher than those described in CASP, which was mainly aimed at prevention of asthma and atopy in children. Preventive effects of N-3 PUFA in the allergy can be observed during pregnancy. Due to different results of the application of N-3 PUFA in pregnant women and later in their children we should conduct further studies in order to evaluate their potential protective properties for allergic diseases [86, 87]

\section{Short-chain fatty acids}

The SCFAs are divided to exogenous and endogenous ones. The former are produced during the fermentation of undigested carbohydrates, hexose oligomers by many bacteria, which colonize the human gastrointestinal tract: Clostridium spp., Eubacterium spp., Fusobacterium spp., Butyrivibrio spp., Megasphaera elsdenii, and Mitsuokella multiacida, Roseburia intestinalis, Faecalibacterium prausnitzii as well as Eubacterium hallii [88]. Undigested plant-origin carbohydrates include: resistant starch, non-starch polysaccharides, oligosaccharides belonging to prebiotics (i.e. inulin), oligofructose, disaccharides (lactose), stachyose, raffinose (sorbitol and mannitol). Endogenous pool includes among others mucins and milk oligosaccharides, being an important source of butyric acid in newborns and infants. Bacterial fermenta- 
tion leads to formation of acetic, propionic and butyric acids and in much smaller amounts - milk, succinic and caproic acids as well as carbon dioxide and hydrogen [88]. Butyric acid in the large intestine is a result of pentose decomposition. Gluconic acid, a prebiotic, considerably stimulates the production of butyrate. In a human, undigested carbohydrates are a source of butyric acid, which is endogenously produced in the large intestine. The carbohydrates include resistant starch and insoluble fractions of dietary fibre [89].

More and more frequently SCFAs are considered to have immunomodulatory properties. They stimulate the growth of saprophytic flora in the intestine by inhibiting the following pathogens: Escherichia coli, Campylobacter, and Salmonella [90]. The SCFAs demonstrate trophic activity on the intestinal epithelium (butyric acid plays the major role of all SCFAs). Besides, butyric acid stimulates the intestinal epithelium to the production of mucus and maintains a proper $\mathrm{pH}$ level in the lumen of the intestine, which additionally protects the gastrointestinal tract against pathogens [88]. SCFAs inhibit the activity of inflammatory mediators in the intestinal epithelium by inhibiting the activation of $\mathrm{NF}-\kappa \mathrm{B}$ in macrophages, which are the main source of cytokines in the inflammatory process in non-specific inflammatory bowel disease. Also here butyric acid appears to be the strongest compound [88].

Scientists constantly conduct studies on preventive properties of diet components with regard to the risk of allergy in children. Results of these studies might help to identify and implement new strategies in prophylaxis and treatment of allergic diseases. In future therapies we will probably manipulate with microbiota and diets. Bearing in mind that a different individual is equipped with different characteristics (genetic polymorphism) we should tailor a diet to each patient. Dietary factors are likely to play a key role in promotion of immunotolerance and prophylaxis of immune diseases. However, any dietary interventions should be carefully considered after analysing all potentially complex interactions.

\section{Conflict of interest}

The authors declare no conflict of interest.

\section{References}

1. Bach JF. The effect of infections on susceptibility to autoimmune and allergic diseases. N Engl J Med 2002; 347: 911-20.

2. Wills-Karp M, Santeliz J, Karp CL. The germless theory of allergic disease: revisiting the hygiene hypothesis. Nat Rev Immunol 2001; 1: 69-75.

3. Martino DJ, Prescott SL. Silent mysteries: epigenetic paradigms could hold the key to conquering the epidemic of allergy and immune disease. Allergy 2010; 65: 7-15.

4. Barker DJ. In utero programming of chronic disease. Clin Sci (Colch) 1998; 95: 115-28.
5. Waterland RA, Travisano M, Tahiliani KG. Diet-induced hypermethylation at agoutiviable yellow is not inherited transgenerationally through the female. FASEB J 2007; 21: 3380-5.

6. Song F, Mahmood S, Ghosh S, et al. Tissue specific differentially methylated regions (TDMR): changes in DNA methylation during development. Genomics 2009; 93: 130-9.

7. Janson PC, Winerdal ME, Winqvist O. At the crossroads of T helper lineage commitment. Epigenetics points the way. Biochim Biophys Acta 2009; 1790: 906-9.

8. Fields PE, Kim ST, Flavell RA. Cutting edge: changes in histone acetylation at the IL-4 and IFN-gamma loci accompany Th1/Th2 differentiation. J Immunol 2002; 169: 647-50.

9. Lee GR, Kim ST, Spilianakis CG, et al. T helper cell differentiation: regulation by cis elements and epigenetics. Immunity 2006; 24: 369-79.

10. Lee DU, Agarwal S, Rao A. Th2 lineage commitment and efficient IL-4 production involves extended demethylation of the IL-4 gene. Immunity 2002; 16: 649-60.

11. Shin HJ, Park HY, Jeong SJ, et al. STAT4 expression in human $T$ cells is regulated by DNA methylation but not by promoter polymorphism. J Immunol 2005; 175: 7143-50.

12. Santangelo S, Cousins DJ, Winkelmann NE, et al. DNA methylation changes at human Th2 cytokine genes coincide with DNase I hypersensitive site formation during CD4(+) T cell differentiation. J Immunol 2002; 169: 1893-903.

13. Akimzhanov AM, Yang XO, Dong C. Chromatin remodelling of interleukin-17 (IL-17)-IL-17F cytokine gene locus during inflammatory helper T cell differentiation. J Biol Chem 2007; 282: 5969-72.

14. Polansky JK, Kretschmer K, Freyer J, et al. DNA methylation controls Foxp3 gene expression. Eur J Immunol 2008; 38: 1654-63.

15. Bollrath J, Powrie FM. Controlling the frontier: regulatory Tcells and intestinal homeostasis. Semin Immunol 2013; 25 : 352-7.

16. Fujimaki W, Takahashi N, Ohnuma K, et al. Comparative study of regulatory $T$ cell function of human CD25CD4 T cells from thymocytes, cord blood, and adult peripheral blood. Clin Dev Immunol 2008; 2008: 305859.

17. Schaub B, Liu J, Hoppler S, et al. Impairment of T-regulatory cells in cord blood of atopic mothers. J Allergy Clin Immunol 2008; 121: 1491-9.

18. Schaub B, Liu J, Schleich I, et al. Impairment of T helper and T regulatory cell responses at birth. Allergy 2008; 63: 1438-47.

19. Strachan D. Hay fever, hygiene, and household size. Br Med J 1989; 299: 1259-60.

20. Blumer N, Herz U, Wegmann M, Renz H. Prenatal lipopolysaccharide-exposure prevents allergic sensitisation and airways inflammation, but not airway responsiveness in a murine model of experimental asthma. Clin Exp Allergy 2005; 35: 397-402.

21. Blumer N, Sel S, Virna S, et al. Perinatal maternal application of Lactobacillus rhamnosus GG suppresses allergic airway inflammation in mouse offspring. Clin Exp Allergy 2007; 37: 348-57.

22. Schaub B, Liu J, Hoppler S, et al. Maternal farm exposure modulates neonatal immune mechanisms through regulatory T cells. J Allergy Clin Immunol 2009; 123: 774-82.

23. Loss G, Apprich S, Waser M, et al. The protective effect of farm milk consumption on childhood asthma and atopy: the GABRIELA study. J Allergy Clin Immunol 2011; 128: 766-73.

24. Lluis A, Depner M, Gaugler B, et al. Protection Against Allergy: Study in Rural Environments Study Group. Increased 
regulatory T-cell numbers are associated with farm milk exposure and lower atopic sensitization and asthma in childhood. J Allergy Clin Immunol 2014; 133: 551-9.

25. El-Gamal YM, Elmasry OA, El-Ghoneimy DH, et al. Immunomodulatory effects of food. Egypt J Pediatr Allergy Immunol 2011; 9: 3-13.

26. Paparo L, di Costanzo M, di Scala C, et al. The influence of early life nutrition on epigenetic regulatory mechanisms of the immune system. Nutrients 2014; 6: 4706-19.

27. De Filippo C, Cavalieri D, Di Paola M, et al. Impact of diet in shaping gut microbiota revealed by a comparative study in children from Europe and rural Africa. Proc Natl Acad Sci U S A 2010; 107: 14691-6.

28. Bunyavanich S, Rifas-Shiman SL, Platts-Mills TA, et al. Peanut, milk, and wheat intake during pregnancy is associated with reduced allergy and asthma in children. J Allergy Clin Immunol 2014; 133: 1373-82.

29. Du Toit G, Roberts G, Sayre PH, et al. Randomized trial of peanut consumption in infants at risk for peanut allergy. N Engl J Med 2015; 372: 803-13.

30. Castellazzi AM, Valsecchi C, Caimmi S, et al. Probiotics and food allergy. Ital J Pediatr 2013; 39: 47.

31. Rautava S, Walker WA. Academy of Breastfeeding Medicine founder's lecture 2008: breastfeeding--an extrauterine link between mother and child. Breastfeed Med 2009; 4: 3-10.

32. Verhasselt $V$. Neonatal tolerance under breastfeeding influence: the presence of allergen and transforming growth factor-b in breast milk protects the progeny from allergic asthma. J Pediatr 2010; 156: S16-20.

33. Devereux G. Early life events in asthma-diet. Pediatr Pulmonol 2007; 42: 663-73.

34. Perdigon G, Alvarez S, Medina M, et al. Influence of the oral administration of lactic acid bacteria on IgA producing cells associated to bronchus. Int I Immunopathol Pharmacol 1999; 12: 97-102.

35. Lee J, Seto D, Bielory L. Meta-analysis of clinical trials of probiotics for prevention and treatment of pediatric atopic dermatitis. J Allergy Clin Immunol 2008; 121: 116-21.

36. Majamaa H, Isolauri E. Probiotics: a novel approach in the management of food allergy. J Allergy Clin Immunol 1997; 99: 179-85.

37. Giovanni M, Agostoni C, Riva E, et al. A randomized prospec tive double blind controlled trial on effects of long-term consumption of fermented milk containing Lactobacillus case in pre-school children with allergic asthma and/or rhinitis. Pediatr Res 2007; 62: 215-20.

38. Björkstén B, Naaber P, Sepp E, et al. The intestinal microflora in allergic Estonian and Swedish 2-year-old children. Clin Exp Allergy 1999; 29: 342-6.

39. Sjögren YM, Jenmalm MC, Böttcher MF, et al. Altered early infant gut microbiota in children developing allergy up to 5 years of age. Clin Exp Allergy 2009; 39: 518-26.

40. Kong HH, Oh J, Deming C, et al. Temporal shifts in the skin microbione associated with disease flares and treatment in children with atopic dermatitis. Genome Res 2012, 22: 850-9.

41. Kalliomäki M, Kirjavainen P, Eerola E, et al. Distinct patterns of neonatal gut microflora in infants in whom atopy was and was not developing. J Allergy Clin Immunol 2001; 107: 129-34.

42. Doege K, Grajecki D, Zyriax BC, et al. Impact of maternal supplementation with probiotics during pregnancy on atopic eczema in childhood - a meta-analysis. Br J Nutr 2012; 107: $1-6$.
43. Kukkonen K, Savilahti E, Haahtela T, et al. Probiotics and prebiotic galacto-oligosaccharides in the prevention of allergic diseases: a randomized, double-blind, placebo-controlled trial. J Allergy Clin Immunol 2007; 119: 192-8.

44. Kopp MV, Hennemuth I, Heinzmann A, et al. Randomized, double blind, placebo-controlled trial of probiotics for primary prevention: no clinical effects of Lactobacillus GG supplementation. Pediatrics 2008; 121: e850-6.

45. Ismail IH, Oppedisano F, Joseph SJ, et al. Prenatal administration of Lactobacillus rhamnosus has no effect on the diversity of the early infant gut microbiota. Pediatr Allergy Immunol 2012; 23: 255-8.

46. Rose MA, Stieglitz F, Köksal A, et al. Efficacy of probiotic Lactobacillus GG on allergic sensitization and asthma in infants at risk. Clin Exp Allergy 2010; 40: 1398-405.

47. Arslanoglu S, Moro GE, Schmitt J, et al. Early dietary intervention with a mixture of prebiotic oligosaccharides reduces the incidence of allergic manifestations and infections during the first two years of life. J Nutr 2008; 138: 1091-5.

48. Tang ML, Lahtinen SJ, Boyle RJ. Probiotics and prebiotics: clinical effects in allergic disease. Curr Opin Pediatr 2010; 22: 626-34.

49. Seaton A, Godden DJ, Brown K. Increase in asthma: a more toxic environment or a more susceptible population? Thorax 1994; 49: 171-4.

50. Black PN, Sharpe S. Dietary fat and asthma: is there a connection? Eur Respir J 1997; 10: 6-12.

51. Calder PC, Albers R, Antoine JM, et al. Inflammatory disease processes and interactions with nutrition. Br J Nutr 2009; 101 (Suppl 1): S1-45.

52. Vassallo MF, Camargo CA Jr. Potential mechanisms for the hypothesized link between sunshine, vitamin D, and food allergy in children. J Allergy Clin Immunol 2010; 126: 217-22.

53. Schnappinger M, Sausenthaler S, Linseisen J, et al. Fish consumption, allergic sensitisation and allergic diseases in adults. Ann Nutr Metab 2009; 54: 67-74.

54. Chatzi L, Apostolaki G, Bibakis, et al. Protective effect of fruits, vegetables and the Mediterranean diet on asthma and allergies among children in Crete. Thorax 2007; 62: 677-83.

55. Arvaniti F, Priftis KN, Papadimitriou A, et al. Adherence to the Mediterranean type of diet is associated with lower prevalence of asthma symptoms, among 10-12 years old children: the PANACEA study. Pediatr Allergy Immunol 2011; 22: 283-9.

56. Seaton A, Godden DJ, Brown K. Increase in asthma: a more toxic environment or a more susceptible population? Thorax 1994; 49: 171-4.

57. Dymarska E, Grochowalska A, Krauss H. Wpływ sposobu odżywiania na układ odpornościowy. Immunomodulacyjne działanie kwasów tłuszczowych, witamin, składników mineralnych oraz przeciwutleniaczy. Nowiny Lekarskie 2013; 82: 222-31.

58. Miyake Y, Sasaki S, Tanaka K, et al. Consumption of vegetables, fruit, and antioxidants during pregnancy and wheeze and eczema in infants. Allergy 2010; 65: 758-65.

59. Krzysik M, Biernat $H$, Grajeta $H$. The influence of chosen nutrients on immune system functioning. Part II. Immunomodulatory effects of vitamins and trace elements on the human body. Adv Clin Exp Med 2007; 16: 123-33.

60. Serhan CN, Yang R, Martin K. Maresins: novel macrofage mediator with potent anti-inflammatory and proresolving actions. J Exp Med 2009; 206: 13-23. 
61. Martindale S, McNeill G, Devereux G, et al. Antioxidant intake in pregnancy in relation to wheeze and eczema in the first two years of life. Am J Respir Crit Care Med 2005; 171 121-8.

62. Litonjua AA, Rifas-Shiman SL, Ly NP, et al. Maternal antioxidant intake in pregnancy and wheezing illnesses in children at 2 y of age. Am J Clin Nutr 2006; 84: 903-11.

63. Devereux G, Turner SW, Craig LC, et al. Low maternal vitamin $E$ intake during pregnancy is associated with asthma in 5-year-old children. Am J Respir Crit Care Med 2005; 171 121-8.

64. Nurmatov U, Devereux G, Sheikh A. Nutrients and foods for the primary prevention of asthma and allergy: systematic review and meta-analysis. J Allergy Clin Immunol 2011; 127 724-33.

65. Sausenthaler S, Koletzko S, Schaaf B, et al. Maternal diet during pregnancy in relation to eczema and allergic sensitization in the offspring at 2 y of age. Am J Clin Nutr 2007; 85: 530-7.

66. Adorini L, Penna G. Dendritic cell tolerogenicity: a key mechanism in immunomodulation by vitamin D receptor agonists. Human Immunol 2009; 70: 345-52.

67. Manavalan JS, Rossi PC, Vlad G, et al. High expression of ILT3 and ILT4 is a general feature of tolerogenic dendritic cells. Transplant Immunol 2003; 11: 245-58a.

68. Chang CC, Ciubotariu R, Manavalan JS, et al. Tolerization of dendritic cells by $T(S)$ cells: the crucial role of inhibitory receptors ILT3 and ILT4. Nat Immunol 2002; 3: 237-43.

69. Liang S, Ristich $\mathrm{V}$, Arase $\mathrm{H}$, et al. A. Modulation of dendritic cell differentiation by HLA-G and ILT4 requires the IL-6STAT3 signaling pathway. Proc Natl Acad Sci USA 2008; 105: 8357-62.

70. Back O, Blomquist HK, Hernell O, et al. Does vitamin D intake during infancy promote the development of atopic allergy? Acta Dermatol Venereol 2009; 89: 28-32

71. Camargo CA Jr, Rifas-Shiman SL, Litonjua AA, et al. Maternal intake of vitamin D during pregnancy and risk of recurrent wheeze in children at 3 y of age. Am J Clin Nutr 2007; 85: 788-95.

72. Devereux G, Litonjua AA, Turner SW, et al. Maternal vitamin D intake during pregnancy and early childhood wheezing. Am J Clin Nutr 2007; 85: 853-9.

73. Erkkola M, Kaila M, Nwaru BI, et al. Maternal vitamin D intake during pregnancy is inversely associated with asthma and allergic rhinitis in 5-year-old children. Clin Exp Allergy 2009; 39: 875-82.

74. Rochat MK, Ege MJ, Plabst D, et al. Maternal vitamin D intake during pregnancy increases gene expression of ILT3 and ILT4 in cord blood. Clin Exp Allergy 2010; 40: 786-94.

75. Shaikh SR, Edidin M. Polyunsaturated fatty acids, membrane organization, T cells, and antigen presentation. Am J Clin Nutr 2006; 84: 1277-89.

76. Field CJ, Schley PD. Evidence for potential mechanisms for the effect of conjugated linoleic acid on tumor metabolism and immune function: lessons from n-3 fatty acids. Am J Clin Nutr 2004; 79 (6 Suppl.): 1190S-8S.

77. Kew S, Mesa MD, Tricon S, et al. Effects of oils rich in eicosa pentaenoic and docosahexaenoic acids on immune cel composition and function in healthy humans. Am J Clin Nutr 2004; 79: 674-81.

78. Calder PC. n-3 polyunsaturated fatty acids, inflammation, and inflammatory diseases. Am J Clin Nutr 2006; 83 (6 Suppl.): 1505S-19S.
79. Peat JK, Salome CM, Woolcock AJ. Factors associated with bronchial hyperresponsiveness in Australian adults and children. Eur Respir J 1992; 5: 921-9.

80. Hodge L, Salome CM, Peat JK, et al. Consumption of oily fish and childhood asthma risk. Med J Aust 1996; 164: 137-40.

81. Haby MM, Peat JK, Marks GB, et al. Asthma in preschool children: prevalence and risk factors. Thorax 2001; 56: 589-95.

82. Furuhjelm C, Warstedt K, Larsson J, et al. Fish oil supplementation in pregnancy and lactation may decrease the risk of infant allergy. Acta Paediatr 2009; 98: 1461-7.

83. Marks GB, Mihrshahi S, Kemp AS, et al. Prevention of asthma during the first 5 years of life: a randomized controlled trial. J Allergy Clin Immunol 2006; 118: 53-61.

84. Nagakura T, Matsuda S, Shichijyo K, et al. Dietary supplementation with fish oil rich in omega-3 polyunsaturated fatty acids in children with bronchial asthma. Eur Respir J 2000; 16: 861-5.

85. Hodge L, Salome CM, Hughes JM, et al. Effects of dietary intake of omega-3 and omega- 6 fatty acids on severity of asthma in children. Eur Respir J 1998; 11: 361-5.

86. Anandan C, Nurmatov U, Sheikh A. Omega 3 and 6 oils for primary prevention of allergic disease: systematic review and meta-analysis. Allergy 2009; 64: 840-8.

87. Toelle BG, Ng KK, Crisafulli D, et al. Eight-year outcomes of the Childhood Asthma Prevention Study. J Allergy Clin Immunol 2010; 126: 388-9.

88. Kuczyńska B, Wasilewska A, Biczysko M, et al. Krótko łańcuchowe kwasy tłuszczowe - mechanizm działania, potencjalne zastosowanie kliniczne oraz zalecenia dietetyczne. Nowiny Lekarskie 2011; 80: 299-304.

89. Kotunia A, Pietrzak P, Guilloteau P, et al. Kwas masłowy w przewodzie pokarmowym. Prz Gastroenterol 2010; 5: 117-22.

90. Roediger WE. Role of anaerobic bacteria in the metabolic welfare of the colonic mucosa in man. Gut 1980; 21: 793-8. 